\title{
INFANT MORTALITY IN AUSTRIA
}

\author{
BY \\ H. CZERMAK AND H. HANSLUWKA
}

Vienna

The exceptionally high mortality in the first year of life has long stimulated research into its causes, the level of the infant mortality rate having been regarded as an indicator of the social and economic well-being of a nation. The dramatic decline in mortality experienced by western countries in the last century has been most pronounced for infancy, childhood, and adolescence. Nevertheless, infant mortality still poses a serious problem in Austria; while in some European countries the infant mortality rate has been reduced to 1.5 to 2 per cent., a value not so long ago being rejected by many experts as impossible, Austria compares relatively unfavourably with these countries, the rate for 1961 (preliminary result) still amounting to as much as 3.3 per cent. While in some countries the fight against infant mortality is being replaced by an active promotion of child health, Austria is but on the threshold of this new era. Whereas in other countries infant mortality data are closely studied, and full use is made of statistics as an objective means for revealing problems, as an aid in finding solutions to them, and in testing the efficiency of measures introduced to overcome them, there exists in Austria a certain lack of figure-mindedness, possibly because of the many disturbances this country has been submitted to, which interrupted a tradition so hopefully begun about 1900 in connexion with such names as those of Teleky, Rosenberg, and Peller.

In this study some aspects of infant mortality in Austria are analysed, the main emphasis being placed upon developments since the turn of the century, regional differences within the country, and causes of death. It is intended to deal with the biological and socio-economic factors connected with infant mortality in a second paper.
Austria has a population of 7 million, of which about 20 per cent. are dependent on agriculture. The country has recently experienced a remarkable economic boom and the population enjoys a relative prosperity, fostered by a generous system of social welfare, the social insurance system covering the great majority of the people. The relationship between the size of the population and the number of physicians is very favourable, about $\mathbf{5 5 0}$ inhabitants per physician, a record which is far better than that observed in most other European countries (Fig. 1, opposite), though some caution must be exercised in interpreting these figures because of possible differces in the delimitation of the group "physicians".

The statistical coverage of births and deaths may be considered satisfactory; although there have been no investigations into the completeness of birth and death registration, the numbers not registered may be dismissed as negligible. The statistical data are tabulated according to year and month of occurrence. The definition of live and stillbirth does not correspond to the recommendations of WHO; the only criterion for live birth in Austria is breathing, whereas, according to WHO, "any sign of life" is the standard. For the present analysis this difference may be disregarded; readers interested in its implications in international comparability are referred to the competent discussion in the United Nations "Handbook of Vital Statistics Methods" (1955). In Austria, for the period under observation, the data on live births and infant deaths may be regarded as internally consistent and comparable; however, some caution must be exercised in interpreting the trend of stillbirths; it may be safely assumed that the lack of a clear legal distinction between stillbirth and abortion before 1938 artificially inflated the number of registered stillbirths up to that date (Rosenfeld, 1903). 
U.S.S.R.

AUSTRIA

CZECHOSLOVAKIA

ITALY

HUNGARY

SWITZERLAND

FED. REP. OF GERMANY

BULGARIA

BELGIUM

DENMARK

GREECE

NORTHERN IRELAND

SCOTLAND

SPAIN

NETHERLANDS

NORWAY

FRANCE

LUXEMBOURG

ENGLAND \&ALES

SWEDEN

POLAND

PORTUGAL

FINLAND

YUGOSLAVIA takes. To improve the situation, from 1963 onwards, a "combined statistical form for deaths" is to be used, whereby the findings of the physician are made directly accessible to the Central Statistical Office which processes the data for all of Austria except the capital, Vienna. The combined form has been in use in Vienna since 1957 where it has brought about a remarkable improvement in accuracy. In spite of the shortcomings of the data, it may be assumed that a critical analysis of the data on the causes of death is useful in making an objective appraisal of the situation.
FIG. 1.- Number of inhabitants per physician in the countries of Europe.
Statistics on the causes of death pose some serious difficulties, especially in the first year of life. In Austria medical certification of death is obligatory, but the statistical form is completed by the local registrar who generally lacks medical knowledge, and this copying of the entries on to the statistical form must be regarded as a source of serious mis-
TRENDS IN INFANT MORTALITY IN AUSTRIA SINCE 1900

The relevant data are contained in Table I, in which total infant mortality is broken up into two components, neonatal* and post-neonatal; figures on stillbirths are also given.

* In Austria neonatal mortality comprises deaths under 1 month post-neonatal mortality deaths from 1 month to under 1 year.

TABLE I

YEARLY AVERAGE BIRTHS AND INFANT DEATHS IN AUSTRIA SINCE 1900, BY QUINQUENNIA

\begin{tabular}{|c|c|c|c|c|c|c|c|c|}
\hline \multirow{3}{*}{ Quinquennium } & \multicolumn{4}{|c|}{ Actual Numbers } & \multicolumn{4}{|c|}{ Rates per 1,000 Live Births } \\
\hline & \multirow{2}{*}{ Live Births } & \multirow{2}{*}{ Stillbirths } & \multicolumn{2}{|c|}{ Deaths at Age less than } & \multirow{2}{*}{ Stillbirths } & \multirow{2}{*}{ Neonatal ${ }^{*}$} & \multirow{2}{*}{$\underset{\text { neonatal }}{\text { Post- }}$} & \multirow{2}{*}{ Infant } \\
\hline & & & 1 month & 1 year & & & & \\
\hline $\begin{array}{c}1900-04 \\
1905-09 \\
1910-14 \\
1915-19 \\
1920-24 \\
1925-29 \\
1930-34 \\
1935-39 \\
1940-44 \\
1945-49 \\
1950-54 \\
1955-59 \\
1960\end{array}$ & $\begin{array}{r}188,153 \\
181,466 \\
168,221 \\
105,588 \\
147,553 \\
122,107 \\
101,773 \\
98,988 \\
129,375 \\
115,664 \\
104,096 \\
117,449 \\
125,945\end{array}$ & $\begin{array}{c}6,639 \\
6,276 \\
= \\
= \\
3, \overline{703} \\
2,887 \\
2,748 \\
2,931 \\
2,447 \\
2,092 \\
2,001 \\
1,916\end{array}$ & $\begin{array}{r}15,258 \\
14,078 \\
11,938 \\
7,431 \\
9,659 \\
6,335 \\
4,865 \\
4,382 \\
4,849 \\
4,837 \\
3,321 \\
3,091 \\
3,094\end{array}$ & $\begin{array}{r}39,787 \\
36,930 \\
30,362 \\
19,997 \\
21,710 \\
14,660 \\
10,198 \\
8,500 \\
9,932 \\
10,694 \\
5,786 \\
5,006 \\
4,727\end{array}$ & $\begin{array}{l}35 \cdot 3 \\
34 \cdot 6 \\
= \\
= \\
30 \cdot 3 \\
28 \cdot 4 \\
27 \cdot 8 \\
22 \cdot 7 \\
21 \cdot 2 \\
20 \cdot 1 \\
17 \cdot 0 \\
15 \cdot 2\end{array}$ & $\begin{array}{l}81 \cdot 1 \\
77 \cdot 6 \\
71 \cdot 0 \\
70 \cdot 4 \\
65 \cdot 5 \\
51 \cdot 9 \\
47 \cdot 8 \\
44 \cdot 3 \\
37 \cdot 5 \\
41 \cdot 8 \\
31 \cdot 9 \\
26 \cdot 3 \\
24 \cdot 6\end{array}$ & $\begin{array}{r}130.5 \\
125.9 \\
109.5 \\
119.0 \\
81.6 \\
68.2 \\
52.4 \\
41.6 \\
39.3 \\
50.7 \\
23.7 \\
16.3 \\
12.9\end{array}$ & $\begin{array}{r}211 \cdot 5 \\
203 \cdot 5 \\
180 \cdot 5 \\
189 \cdot 4 \\
147 \cdot 1 \\
120 \cdot 1 \\
100 \cdot 2 \\
85 \cdot 9 \\
76 \cdot 8 \\
92 \cdot 5 \\
55 \cdot 6 \\
42.6 \\
37 \cdot 5\end{array}$ \\
\hline
\end{tabular}

* In the first month of life.

t In the second to twelfth month of life.

IIn the first year of life. 
While infant mortality declined by 82 per cent., the neonatal rate decreased by 70 per cent. and the post-neonatal rate by as much as 90 per cent. The influence of the two world wars is brought out sharply by the increase in the rates for 1915-19 and 1945-49, the average for the latter period being raised by the very high peak in 1945 (16 per cent.). The decrease in infant mortality before the first world war seemed to gain momentum; a decrease of 4 per cent. between 1900-04 and 1905-09 was followed by a decrease of 11 per cent. between 1905-09 and 1910-14. Between 1920-24, 1925-29, and 1930-34, however, the rates of decrease were about 20 per cent., i.e. higher than before 1914 . When viewing the latest development, the disturbances of the second world war and the disastrous situation in 1945 must be taken into account. The declining trend in neonatal mortality was interrupted in $1945-49$ by a rise, whereas after the first world war the rate for 1915-19 had been somewhat lower than that for the preceding quinquennium. Spectacular declines in post-neonatal mortality were registered for 1920-24 and 1950-54, the diminution amounting to 32 and 53 per cent. respectively, when compared with the preceding periods. The dependence of post-neonatal mortality on external influences is strikingly demonstrated, whereas neonatal mortality is not so sensitive.

It is interesting to assume that the decrease in infant mortality in Austria may be expressed by a straight line. When fitting the observed data by least squares, the results are in remarkably close agreement with this hypothesis (Fig. 2), especially when due attention is paid to the disturbances caused by the two world wars.

The agreement is still better for stillbirths (Fig. 3, opposite), for which trends and observed values practically coincide. (In order to show the development more clearly, a different scale is used; for the years 1911-21 no data are available.)

The average yearly rate of decrease for infant mortality is 3.5 per cent., for neonatal mortality

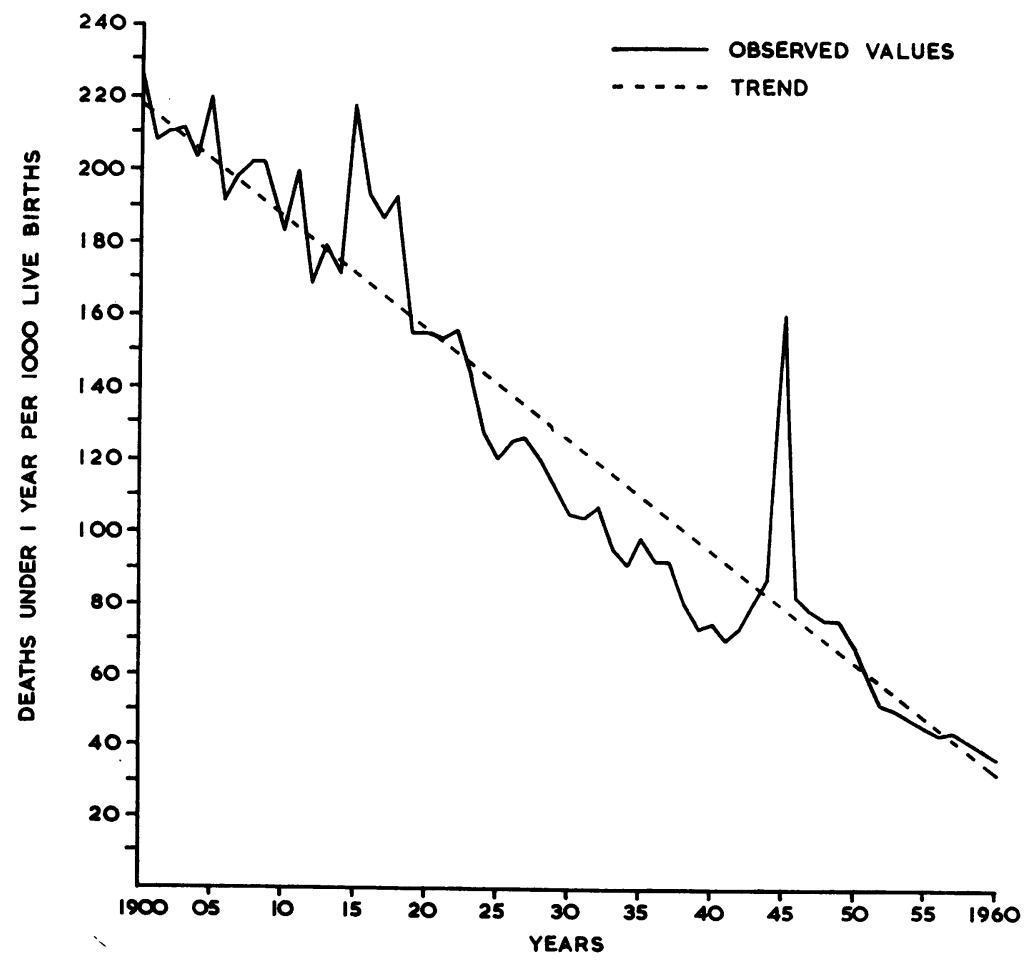

FIG. 2.-Infant deaths under one year per 1,000 live births, 1900-1960 


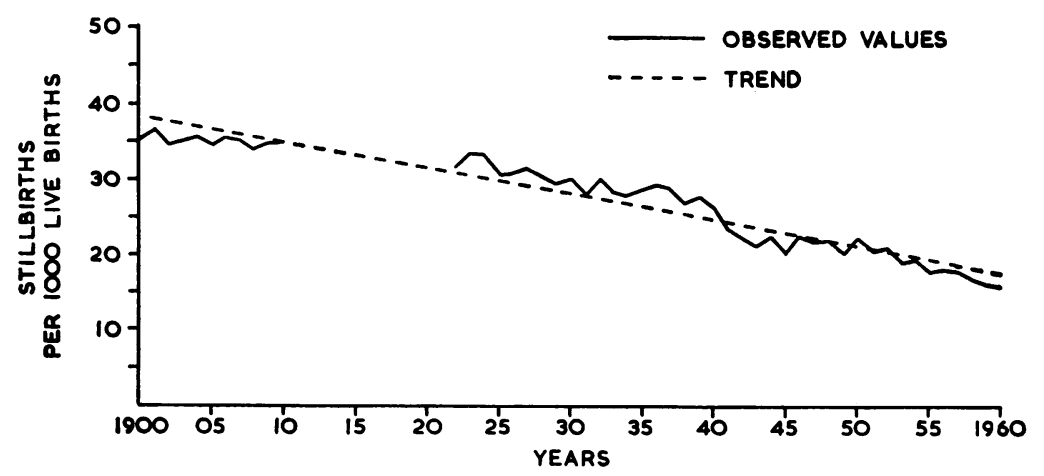

FiG. 3.-Stillbirths per 1,000 live births, 1900-1960

$2 \cdot 2$ per cent., and for post-neonatal mortality 6 per cent. (For comparison the average yearly rate of decrease for stillbirths is 1 per cent.)

Thanks to the suggestions of Peller (1947-48) perinatal mortality is also studied. In Austria perinatal mortality is regarded as comprising stillbirths and deaths in the first week of life, and the data which are available since 1927 reveal a reduction from 62 (per 1,000 live births) to 35, which amounts to a 43 per cent. decline. In the same period neonatal mortality was cut by 52 per cent., post-neonatal mortality by 83 per cent., and total infant mortality by 70 per cent. These figures prove that the main success in combating infant mortality was achieved in the post-neonatal period which is very sensitive to improvements in living and sanitary conditions, whereas perinatal mortality must be regarded as a serious problem still confronting us. Nonetheless, a post-neonatal rate of $1 \cdot 3$ per cent. is unfavourable when judged from an international point of view, for some countries show post-neonatal rates of 0.5 per cent. and less. These figures also confirm the hypothesis that a reduction of infant mortality in Austria by about 1 per cent. must be termed a realistic short-term goal.

A break-down according to sex shows that there are practically no differences since 1900 ; for males the rate has declined by 82 per cent., and for females by 83 per cent. When the male rate is expressed as a percentage of the female rate, excess male mortality is shown to have increased from 20 to 28 per cent. For 1955-59 the male excess in the neonatal and post-neonatal period was about the same, but the figures for 1960 suggest a higher male excess in the post-neonatal period.

Table II shows the figures for legitimacy and

TABLE II

YEARLY AVERAGE INFANT MORTALITY IN AUSTRIA SINCE 1900, BY LEGITIMACY

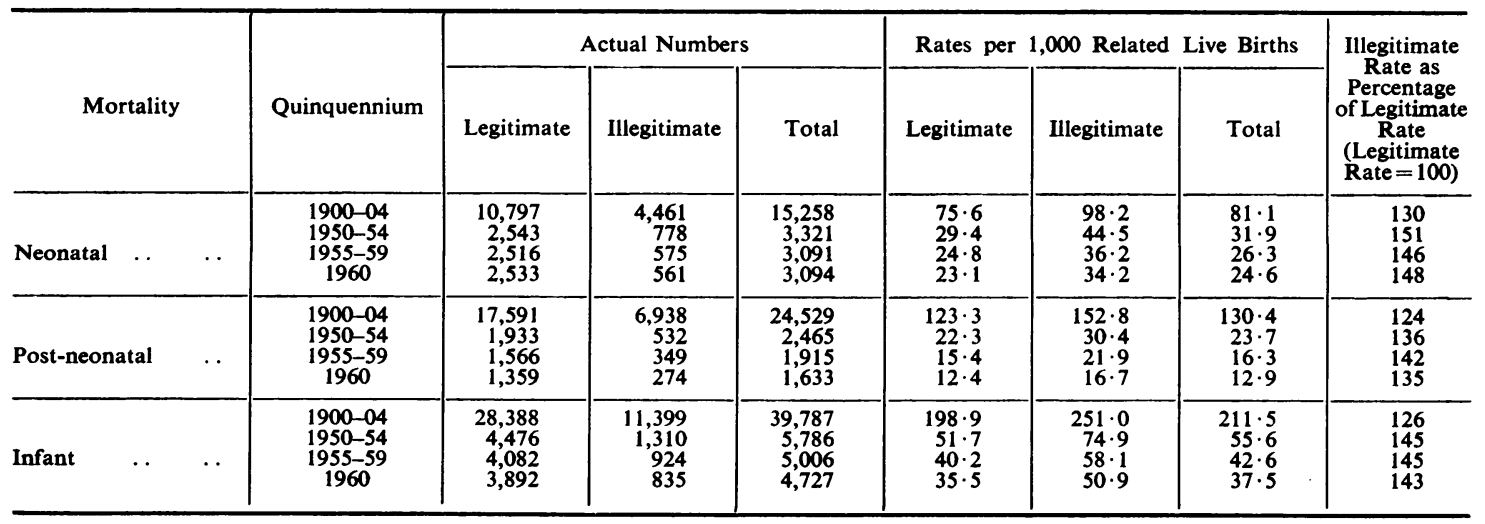


illegitimacy. The rate for legitimate children was reduced by 82 per cent., and for the illegitimate by 80 per cent. The ratio between the two rates increased from 1.26 to 1.43 . It is interesting to note that in post-neonatal mortality the decreases are almost the same, but in neonatal mortality a decrease of 69 per cent. for legitimates is contrasted with 65 per cent. for illegitimates. However, it must be borne in mind that these figures probably overstate the infant mortality of legitimates and understate that of illegitimates, because a live birth may be registered as illegitimate and later legitimized by marriage so that the baby is registered as legitimate at the time of death. To our regret, no data on legitimation are available, though it is generally regarded as a not unimportant factor. However that may be, the greater risks to illegitimate children cannot be disputed; only the extent of the difference may be underestimated.

\section{Regional Differences}

Data on infant mortality by regional subdivisions are based on the usual place of residence of the parents, and not on the place of occurrence. Table III contains figures on infant mortality by provinces since 1955-59. (Austria has nine provinces, the number of the inhabitants varying greatly-between 200,000 and 1.7 million; there are also marked differences in the socio-economic structure.)

TABLE III

INFANT MORTALITY, BY PROVINCES, 1955-61

\begin{tabular}{|c|c|c|c|c|c|c|c|}
\hline \multirow{4}{*}{ Province } & \multicolumn{7}{|c|}{ Deaths at Age less than 1 Year } \\
\hline & \multicolumn{3}{|c|}{ Actual Numbers } & \multicolumn{4}{|c|}{ Rates per 1,000 Live Births } \\
\hline & \multirow{2}{*}{$\underset{59}{1955-}$} & \multirow[b]{2}{*}{1960} & \multirow[b]{2}{*}{$1961^{*}$} & \multirow{2}{*}{$\begin{array}{c}1955- \\
59\end{array}$} & \multicolumn{2}{|c|}{1960} & \multirow[b]{2}{*}{$1961^{*}$} \\
\hline & & & & & Crude & $\begin{array}{l}\text { Cor- } \\
\text { rected }\end{array}$ & \\
\hline $\begin{array}{l}\text { Vienna } \\
\text { Lower Austria } \\
\text { Burgenland } \\
\text { Upper Austria } \\
\text { Salzburg } \quad . \\
\text { Styria } \\
\text { Carinthia } \quad \ldots \\
\text { Tyrol _. } \\
\text { Vorariberg } \quad .\end{array}$ & $\begin{array}{r}610 \\
1,060 \\
282 \\
881 \\
264 \\
946 \\
465 \\
317 \\
181\end{array}$ & $\begin{array}{l}579 \\
967 \\
249 \\
817 \\
269 \\
874 \\
476 \\
318 \\
178\end{array}$ & $\begin{array}{l}581 \\
864 \\
161 \\
820 \\
270 \\
784 \\
374 \\
305 \\
149\end{array}$ & $\begin{array}{l}42 \cdot 8 \\
44 \cdot 9 \\
53 \cdot 8 \\
40 \cdot 2 \\
39 \cdot 6 \\
44 \cdot 4 \\
44 \cdot 5 \\
34 \cdot 2 \\
38 \cdot 1\end{array}$ & $\begin{array}{l}33 \cdot 4 \\
38 \cdot 7 \\
47 \cdot 8 \\
34 \cdot 7 \\
37 \cdot 6 \\
40 \cdot 2 \\
44 \cdot 9 \\
31 \cdot 6 \\
33 \cdot 4\end{array}$ & $\begin{array}{l}34 \cdot 5 \\
40 \cdot 4 \\
48 \cdot 4 \\
36 \cdot 1 \\
39 \cdot 8 \\
41 \cdot 9 \\
46 \cdot 4 \\
33 \cdot 7 \\
34 \cdot 6\end{array}$ & $\begin{array}{l}31 \cdot 1 \\
34 \cdot 0 \\
37 \cdot 6 \\
33 \cdot 1 \\
33 \cdot 8 \\
34 \cdot 5 \\
35 \cdot 9 \\
27 \cdot 7 \\
26 \cdot 2\end{array}$ \\
\hline $\begin{array}{l}\text { Whole of } \\
\text { Austria }\end{array}$ & 5,006 & 4,727 & 4,308 & $42 \cdot 6$ & $37 \cdot 5$ & $39 \cdot 1$ & $32 \cdot 9$ \\
\hline
\end{tabular}

* Provisional data.

In Table III the figures speak for themselves; only the column "corrected rates" requires an explanation. Usually the number of infant deaths in a particular year is related to the number of live births in the same year, notwithstanding the fact that infant deaths in a calendar year are composed of two birth cohorts, the year under observation and the preceding one. On the whole, this incorrect measuring does not seriously affect the picture. However, if there are marked differences in the yearly number of births, the true situation may be wrongly reflected. Therefore, in the Austrian Central Statistical Office, in addition to the usual procedure, corrected rates are calculated on basis of the method proposed by Valaoras (1950), which allows for differences in the yearly number of live births. The corrected rate is 1.6 points higher than the crude rate. In the period under observation, Tyrol and Vorarlberg have a good record which is in line with past experience. On the other side, Burgenland and Carinthia are still lagging behind. An analysis of data for 1930-34 and 1950-54 revealed that-notwithstanding the general decline in infant mortality-the ranking of the provinces has remained practically unaltered.

The same picture held for political districts; on the whole, those which had good records some $\mathbf{3 0}$ years ago are still in a favourable position to-day, whereas, with a few exceptions districts with poor records are still lagging behind.

Table IV groups the political districts by the infant mortality rate; between $1950-54$ and $1955-59$ there was a small change in the number of admini strative units which may safely be disregarded.

TABLE IV

REGIONAL DIFFERENCES IN INFANT MORTALITY RATES IN AUSTRIA, BY POLITICAL DISTRICTS, 1950-1960

\begin{tabular}{|c|c|c|c|c|}
\hline \multirow{2}{*}{\multicolumn{2}{|c|}{$\begin{array}{c}\text { Mortality Rates } \\
\text { per 1,000 Live Births }\end{array}$}} & \multicolumn{3}{|c|}{$\begin{array}{l}\text { Number of Political Districts } \\
\text { with Given Rate }\end{array}$} \\
\hline & & $1950-54$ & $1955-59$ & 1960 \\
\hline \multirow[t]{2}{*}{ Infant } & $\begin{array}{c}\text { Under } 25 \\
25-30 \\
30-35 \\
35-40 \\
40-45 \\
45-50 \\
50 \text { and Over }\end{array}$ & $\begin{array}{l}- \\
\\
4 \\
8 \\
13 \\
69\end{array}$ & $\begin{array}{l}-2 \\
12 \\
21 \\
23 \\
19 \\
19\end{array}$ & $\begin{array}{r}5 \\
9 \\
25 \\
24 \\
9 \\
9 \\
15\end{array}$ \\
\hline & Total $\quad \ldots$ & 94 & 96 & 96 \\
\hline \multirow[t]{2}{*}{ Neonatal } & $\begin{array}{c}\text { Under } 25 \\
25-30 \\
30-35 \\
35 \text { and Over }\end{array}$ & $\begin{array}{r}7 \\
20 \\
49 \\
18\end{array}$ & $\begin{array}{r}39 \\
40 \\
16 \\
1\end{array}$ & $\begin{array}{r}55 \\
20 \\
12 \\
9\end{array}$ \\
\hline & Total & 94 & 96 & 96 \\
\hline \multirow[t]{2}{*}{ Postneonatal } & $\begin{array}{c}\text { Under } 10 \\
10-15 \\
15-20 \\
20-25 \\
25 \text { and Over }\end{array}$ & $\begin{array}{r}1 \\
7 \\
18 \\
20 \\
48\end{array}$ & $\begin{array}{r}7 \\
27 \\
29 \\
27 \\
6\end{array}$ & $\begin{array}{r}23 \\
41 \\
22 \\
4 \\
6\end{array}$ \\
\hline & Total & 94 & 96 & 96 \\
\hline
\end{tabular}

When interpreting the figures, due attention must be paid to the fact that the grouping for 1950-54 and 
1955-59 is based on 5-year averages in contrast to 1960 which relates only to one year and is therefore more subject to random influences. Nonetheless, some instructive conclusions may be drawn. While in 1950-54 only four political districts had rates of less than 4 per cent., by 1960 two-thirds (63) had reached this level. While in 1955-59 the rate was less than 3 per cent. in only two districts, by 1960 there were fourteen such districts. Meanwhile the districts with an infant mortality of 5 per cent. or more decreased from 69 in 1950-54 to fifteen in 1960.

Whereas in 1950-54 only one district had a postneonatal rate of less than 1 per cent., in 1955-59 there were seven, and in 1960 there were 23 . There can be no doubt that the results achieved to-day by the "best" districts will constitute the average of tomorrow, and those which still lag behind will catch up. It is here that planned measures must be taken for accelerating this improvement. These regional differences reveal those places where help is most urgently needed and also give a clue to what may be regarded as a reasonable short-term goal. These regional differences were examined to find out if there was a consistent pattern in socio-economic structure. When the districts were grouped by the percentage of the population dependent on agriculture in the 1951 census and the infant mortality rate for 1950-54, a highly significant coefficient of correlation was found: $r=0.56$. According to the regression equations, a rise in the proportion of the agricultural population by 1 per cent. is accompanied by an increase in infant mortality by 0.94 per 1,000 live births.

The question must be asked how far differences between the political districts are due to random influences and how far they expose "true" discrepancies. The analysis of variance shows that about 75 per cent. of the discrepancies have a material foundation (Hansluwka, 1959).

\section{Causes of Death}

Data on infant mortality by causes of death are available since 1938 (Table V). In order to achieve comparability, it was impossible to avoid some heterogeneity in the groups of causes which was due to changes in the classification system and the scope of the tabulation programme.

The difficulties inherent in all new statistics are clearly manifested in the data for 1938 to 1940 ; it seems, therefore, safer to start the analysis with the year 1941, which may be termed "normal" in so far as up to (and including) this year, the war did not cause any extraordinary disturbances. Absolute figures are not given since they are not comparable because of boundary changes during the German occupation of Austria.

TABLE V

INFANT MORTALITY RATES IN AUSTRIA, BY CAUSE OF DEATH, 1938-60

\begin{tabular}{|c|c|c|c|c|c|c|c|c|}
\hline \multirow[b]{2}{*}{ Year } & \multicolumn{8}{|c|}{ Infant Deaths per 10,000 Live Births } \\
\hline & $\begin{array}{c}\text { (1) } \\
\text { Infectious } \\
\text { Diseases }\end{array}$ & $\begin{array}{l}\text { (2) } \\
\text { Diseases of } \\
\text { Respiratory } \\
\text { Tract }\end{array}$ & $\begin{array}{c}\text { (3) } \\
\text { Gastric and } \\
\text { Intestinal } \\
\text { Catarrh }\end{array}$ & $\begin{array}{l}\text { (4) } \\
\text { Diseases } \\
\text { peculiar } \\
\text { to Early } \\
\text { Infancy }\end{array}$ & $\begin{array}{c}\text { (5) } \\
\text { Congenital } \\
\text { Malformation }\end{array}$ & $\begin{array}{c}\text { (6) } \\
\text { Accidents }\end{array}$ & $\begin{array}{l}\text { All Other } \\
\text { Causes }\end{array}$ & Total \\
\hline $\begin{array}{l}1938 \\
1939 \\
1940 \\
1941 \\
1942 \\
1943 \\
1944 \\
1945 \\
1946 \\
1947 \\
1948 \\
1949 \\
1950 \\
1951 \\
1952 \\
1953 \\
1954 \\
1955 \\
1956 \\
1957 \\
1958 \\
1959 \\
1960\end{array}$ & $\begin{array}{r}39 \cdot 0 \\
51 \cdot 2 \\
41 \cdot 5 \\
41 \cdot 4 \\
48 \cdot 1 \\
51 \cdot 0 \\
51 \cdot 4 \\
114 \cdot 6 \\
50 \cdot 1 \\
43 \cdot 4 \\
42 \cdot 4 \\
39 \cdot 1 \\
25 \cdot 8 \\
24 \cdot 1 \\
12 \cdot 8 \\
11 \cdot 6 \\
14 \cdot 7 \\
10 \cdot 1 \\
7 \cdot 4 \\
9 \cdot 3 \\
7 \cdot 2 \\
8 \cdot 4 \\
3 \cdot 7\end{array}$ & $\begin{array}{r}171 \cdot 2 \\
160 \cdot 7 \\
152 \cdot 3 \\
164 \cdot 9 \\
153 \cdot 1 \\
168 \cdot 9 \\
200 \cdot 0 \\
278 \cdot 2 \\
126 \cdot 7 \\
139 \cdot 0 \\
149 \cdot 2 \\
164 \cdot 4 \\
129 \cdot 2 \\
133 \cdot 3 \\
89 \cdot 4 \\
93 \cdot 8 \\
90 \cdot 6 \\
87.0 \\
84 \cdot 3 \\
84 \cdot 5 \\
76 \cdot 3 \\
70 \cdot 2 \\
65 \cdot 0\end{array}$ & $\begin{array}{r}48 \cdot 1 \\
49 \cdot 5 \\
84 \cdot 6 \\
83 \cdot 5 \\
114 \cdot 5 \\
123 \cdot 1 \\
157 \cdot 8 \\
490 \cdot 5 \\
125 \cdot 3 \\
117 \cdot 7 \\
104 \cdot 3 \\
91 \cdot 6 \\
79 \cdot 3 \\
58 \cdot 9 \\
49 \cdot 4 \\
35 \cdot 5 \\
42 \cdot 2 \\
39 \cdot 4 \\
40 \cdot 7 \\
36 \cdot 8 \\
30 \cdot 4 \\
35 \cdot 1 \\
29 \cdot 8\end{array}$ & $\begin{array}{l}330 \cdot 1 \\
281 \cdot 2 \\
263 \cdot 7 \\
240 \cdot 0 \\
247 \cdot 6 \\
258 \cdot 8 \\
275 \cdot 6 \\
474 \cdot 6 \\
342 \cdot 4 \\
307 \cdot 0 \\
292 \cdot 6 \\
272 \cdot 8 \\
265 \cdot 2 \\
252 \cdot 5 \\
218 \cdot 8 \\
201 \cdot 5 \\
176 \cdot 3 \\
169 \cdot 6 \\
156 \cdot 7 \\
154 \cdot 5 \\
148 \cdot 8 \\
140 \cdot 8 \\
125 \cdot 8\end{array}$ & $\begin{array}{l}5 \cdot 4 \\
14 \cdot 5 \\
35 \cdot 5 \\
35 \cdot 1 \\
33 \cdot 4 \\
41 \cdot 9 \\
40 \cdot 2 \\
35 \cdot 3 \\
28 \cdot 9 \\
36 \cdot 4 \\
37 \cdot 8 \\
42 \cdot 6 \\
40 \cdot 1 \\
39 \cdot 6 \\
43 \cdot 5 \\
41 \cdot 2 \\
42 \cdot 1 \\
43 \cdot 4 \\
40 \cdot 6 \\
46 \cdot 8 \\
45 \cdot 3 \\
46 \cdot 6 \\
48 \cdot 8\end{array}$ & $\begin{array}{l}3 \cdot 2 \\
2 \cdot 3 \\
3 \cdot 6 \\
3 \cdot 9 \\
5 \cdot 7 \\
4 \cdot 8 \\
5 \cdot 7 \\
12 \cdot 4 \\
7 \cdot 3 \\
7 \cdot 1 \\
3 \cdot 9 \\
4 \cdot 8 \\
5 \cdot 7 \\
4 \cdot 0 \\
3 \cdot 6 \\
4 \cdot 4 \\
4 \cdot 2 \\
3 \cdot 9 \\
5 \cdot 2 \\
5 \cdot 1 \\
5 \cdot 8 \\
6 \cdot 6 \\
5 \cdot 2\end{array}$ & $\begin{array}{r}204 \cdot 1 \\
178 \cdot 9 \\
166 \cdot 4 \\
134 \cdot 8 \\
142 \cdot 6 \\
149 \cdot 5 \\
155 \cdot 0 \\
210 \cdot 9 \\
133 \cdot 4 \\
132 \cdot 5 \\
132 \cdot 0 \\
137 \cdot 2 \\
115 \cdot 3 \\
100 \cdot 6 \\
101 \cdot 6 \\
111 \cdot 2 \\
112 \cdot 9 \\
102 \cdot 2 \\
97 \cdot 7 \\
105 \cdot 2 \\
93 \cdot 2 \\
90 \cdot 3 \\
97 \cdot 0\end{array}$ & $\begin{array}{r}801 \cdot 1 \\
738 \cdot 3 \\
747 \cdot 6 \\
703 \cdot 6 \\
745 \cdot 0 \\
798 \cdot 0 \\
885 \cdot 7 \\
1,616 \cdot 5 \\
814 \cdot 1 \\
783 \cdot 1 \\
762 \cdot 2 \\
752 \cdot 5 \\
660 \cdot 6 \\
613 \cdot 0 \\
519 \cdot 1 \\
499 \cdot 2 \\
483 \cdot 0 \\
455 \cdot 6 \\
432 \cdot 6 \\
442 \cdot 2 \\
407 \cdot 0 \\
398 \cdot 0 \\
375 \cdot 3\end{array}$ \\
\hline $\begin{array}{c}1960 \\
(1941=100)\end{array}$ & $8 \cdot 9$ & $39 \cdot 4$ & $35 \cdot 7$ & $52 \cdot 4$ & $139 \cdot 0$ & $133 \cdot 3$ & $72 \cdot 0$ & $53 \cdot 3$ \\
\hline
\end{tabular}

(1)-(6) Detailed List of International Statistical Classification of Diseases, Injuries, and Causes of Death
(1) $001-138$
(2) $470-527,763$
(3) $571-2,764$
(5) $750-759$ 
Noteworthy reductions are seen for infant mortality as a whole and for most of the causes of death shown in Table $\mathrm{V}$, the two exceptions being congenital malformation and accidents. The rising trend in the death rate due to congenital malformation is statistically significant at the 1 per cent. level (according to the $\chi^{2}$ test). In 1960 about 20 per cent. of infant deaths were assigned to three groups: infectious diseases, diseases of the respiratory tract, and gastric and intestinal catarrh, causes which, in the leading countries of the West, are relatively seldom fatal. For instance, in Sweden and the Netherlands, only two and one per 10,000 live births respectively died from gastric and intestinal catarrh, whereas in Austria in 1958 the rate was 30 per 10,000 live births. Since 1953 there has been no marked reduction in the deaths due to this cause, although Austria still has so far to go to reach the possible minimum.

An analysis of regional differences in causes of death by provinces proves that the rates for Austria are weighted averages of varying provincial values. Calculating the standard deviations for the groups studied and expressing the results as percentages of the arithmetic mean (the rate for Austria as a whole), the following values are obtained for the coefficients of variation:

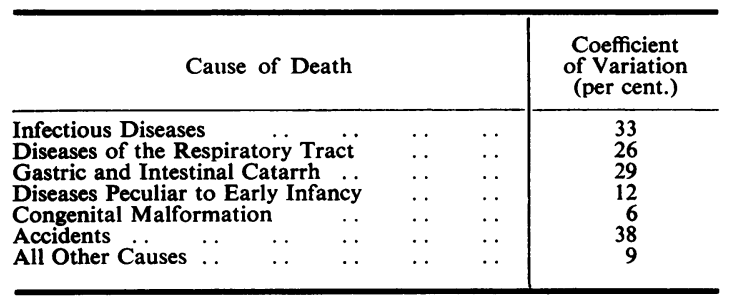

As expected, congenital malformation exhibits little variance; great differences are shown for accidents, infectious diseases, diseases of the respiratory tract, and gastric and intestinal catarrh. A more penetrating analysis (Czermak and Hansluwka, 1962) discloses that differences in mortality due to the three last-mentioned causes are statistically significant and can hardly be explained away, even if possible differences in diagnostic standards are taken into account. Reducing the mortality from these three causes to the lowest level observed in any province, would bring about a decline in the yearly number of infant deaths by 600 (about 13 per cent.).

\section{SUMMARY}

(1) Some aspects of infant mortality in Austria, especially developments since 1900 , regional differences, and causes of death are discussed. The importance of certain biological and social factors is to be analysed in a second paper.

(2) Since 1900 infant mortality has declined by 82 per cent., neonatal mortality by 70 per cent., and post-neonatal mortality by 90 per cent. For stillbirths the fall by 57 per cent. which has been registered probably overstates the true position (because of differences in definition). The average yearly rate of decrease is $\mathbf{2} \cdot \mathbf{2}$ per cent. for neonatal mortality, 6 per cent. for post-neonatal mortality 3.5 per cent. for total infant mortality, and 1 per, cent. for stillbirths.

(3) An analysis of regional differences by provinces (9) and political districts (96) reveals marked differences which can not be due to chance. The districts which had a bad record some 30 years ago are, on the whole, still lagging behind, and there has been little change in the ranking of the districts.

(4) Data on causes of death show a sharp decline for most causes, accidents and congenital malformation being exceptions. The increase in the rate for the last-named is statistically significant. In spite of a fall by 60 per cent. in infant mortality from diseases of the respiratory tract and gastric and intestinal catarrh, these two causes accounted for a quarter of the deaths of infants under 1 year in the period 1956-60. These two causes play an important role in the post-neonatal period and are very sensitive to environmental influences.

(5) There are marked differences between the findings in the various provinces, especially in infectious diseases, diseases of the respiratory tract, and gastric and intestinal catarrh. A reduction in the mortality due to these three causes to the lowest level observed would mean a fall of about 600 in the yeally total of infant deaths.

\section{REFERENCES}

Czermak, H., and Hansluwka, H. (1962). Münch. med. Wschr., 104, No. 31.

Hansluwka, H. (1959). "Die Säuglingssterblichkeit in Osterreich". International Bevölkerungswissenschaftlicher Congress, Vienna.

Peller, S. (1947-48). Population Stud., 1, 405.

Rosenfeld, S. (1903). Statist. Mschr. (Wien), n.s. 8, 293. United Nations (1955). "Handbook of Vital Statistics Methods". Studies in Methods, Series F, No. 7. U.N.O., New York.

Valaoras, V. G. (1950). Population Stud., 4, 253. 